\title{
Pre-Procedural Blood Glucose Level and Contrast-Induced Nephropathy after Percutaneous Coronary Intervention in Non Diabetic Patients with Acute Coronary Syndrome
}

\author{
Md. Zillur Rahman, Abdullah Al Shafi Majumder, Nazir Ahmed Chowdhury, Mesbauddin Ahmed \\ Department of Cardiology, National Institute of Cardiovascular Disease, Dhaka
}

Key Words : CIN, PCI, $A C S$

\begin{abstract}
:
Background: Contrast induced nephropathy (CIN) is not an uncommon complication of percutaneous coronary intervention (PCI) and it is more in diabetic patients. But we do not know the incidence and consequences of CIN of patients with high blood sugar but not known diabetic. We planned to find the relationship between level of admission blood glucose and contrast induced nephropathy after PCI in Acute Coronary Syndrome (ACS) in non-diabetic patients.

Methods: This prospective observational study was conducted in National Institute of Cardiovascular Diseases, Dhaka from January 2012 to June 2012. Total 120 patients were observed in two groups, group-I non-diabetic with normal blood glucose $(\leq 7.8 \mathrm{mmol} / \mathrm{L})$ and group-II non-diabetic with high blood glucose $(\geq 7.8 \mathrm{mmol} / \mathrm{L})$.

Results: Results show increase in serum creatinine $(0.1 \mathrm{mg} / \mathrm{dl}$ vs. $0.3 \mathrm{mg} / \mathrm{dl})$ and decrease in creatinine clearance rate $(12.9 \mathrm{ml} / \mathrm{min}$ vs. $6.0 \mathrm{ml} / \mathrm{min})$ was more in hyperglycemic than normoglycemic. When most common definition of contrast induced nephropathy was used, the incidence of CIN was 24\% in high blood glucose group and 4\% in normal blood glucose group ( $p=0.004)$. The higher the admission blood glucose level there is more incidence of contrast induced nephropathy. Multivariate analysis of factors associated with CIN shows that patients with high blood glucose $(>7.8 \mathrm{mmol} / \mathrm{l})$ and $>150 \mathrm{ml}$ of contrast exposure are independent predictors of contrast induced nephropathy. The patients subjected to PCI having high blood glucose were at 6 times higher risk of developing CIN than normal blood glucose and use of contrast $>150 \mathrm{ml}$ were more than 2 times higher risk of developing CIN.

Conclusion: Patients with high blood sugar on admission of ACS patients have more chance of developing CIN after PCI.
\end{abstract}

(Cardiovasc. j. 2017; 9(2): 106-115)

\section{Introduction:}

Contrast induced nephropathy (CIN) is generally defined as an increase in serum creatinine concentration of $>0.5 \mathrm{mg} / \mathrm{dl}(>44 \mu \mathrm{mol} / \mathrm{L})$ or $25 \%$ above baseline within 48 hours after contrast administration. ${ }^{1}$ Most recently, the acute kidney injury network has defined contrast- induced AKI as a rise in the serum creatinine level $\geq 0.3 \mathrm{mg} / \mathrm{dl}$ or an increase in the serum creatinine level of $\geq 50 \%$ from baseline that occurred within 48 hour after coronary angiography. ${ }^{2}$ The use of iodinated

contrast media has been described as the third most common cause of hospital acquired renal insufficiency. It commonly occurring after coronary angiography and/or angioplasty and computed tomography scans. ${ }^{3}$ It occurs within 24 48 hours of exposure, with creatinine level typically peaking 3-5 days after procedure and returning to baseline or near baseline in 1-3 weeks. ${ }^{4}$

Patients with or without a prior history of DM may present with hyperglycemia during acute coronary syndrome. Among patients with no prior history of

Address of Correspondence: Dr. Md. Zillur Rahman, Department of Cardiology, National Institute of Cardiovascular Disease, Dhaka. 
DM, hyperglycemia may reflect previously undiagnosed diabetes, pre-existing glucose intolerance, stress-related carbohydrate intolerance, or a combination of these. ${ }^{5}$ Several studies revealed that elevated blood glucose in non diabetic patients in admission associated with bad outcome and subsequent increased cardiovascular adverse events including $\mathrm{CHF}$, cardiogenic shock and death. ${ }^{5}$

A higher percentage of the hyperglycemic nondiabetic suffered cardiac arrest before admission compared with hyperglycemic DM (15\% and $2 \%$ respectively). ${ }^{6} \mathrm{~A}$ recent report showed that, the patients who had no known diabetes at the time of $\mathrm{AMI}$ and whose admission blood glucose levels were less than $200 \mathrm{mg} / \mathrm{dL}(<11.1 \mathrm{mmol} / \mathrm{L})$, up to $40 \%$ were diagnosed as having impaired glucose tolerance and $25 \%$ have developed diabetes when tested 3 months after discharge. ${ }^{7}$

High glucose appears to be a much stronger predictor of adverse events in patients without previously recognized diabetes than in those with established diabetes. ${ }^{8}$ The incidence of radiographic contrast agent-induced acute renal failure is estimated to be as high as 5.7\%-29.4\% among patients with diabetes mellitus and $14.8 \%$ to $55 \%$ in patients with chronic renal insufficiency, though the incidence is $<2 \%$ in general population. ${ }^{9}$

Patients having eGFR $>60 \mathrm{ml} / \mathrm{min}$ has very low risk for CIN and these patients require no specific prophylaxis or follow up. eGFR 45-59 $\mathrm{ml} / \mathrm{min}$ has low risk for CIN and in the absence of additional risk factors these patients require no specific prophylaxis or follow up. eGFR $<45 \mathrm{ml} / \mathrm{min}$ moderate risk for CIN and preventive measures are recommended. ${ }^{10}$

The lowest rate of CIN occurs in patients receiving less than 100 to $140 \mathrm{ml}$ of contrast. Contrast volume in excess of $5 \mathrm{ml} / \mathrm{kg}$ strongly predicts nephropathy requiring dialysis. A significantly increased risk of CIN has also been demonstrated among patients who received a second dose of contrast media within 48 hours. ${ }^{10}$ Another study has shown that, the incidence of contrast induced nephropathy in anemic patients is more (26\%) after PCI, than with normal hemoglobin (8\%). ${ }^{11}$

However, while diabetes is a well recognized risk factor for CI-AKI, the association between preprocedural blood glucose levels and CI-AKI risk (regardless of pre-existing diabetes) is unknown. Thus, it is possible that a combination of admission hyperglycemia in non-diabetic ACS patients and contrast exposure during PCI could significantly increase the risk for CI-AKI. ${ }^{12,13}$

Since hyperglycemia occurs in over $40 \%$ of ACS patients, nearly half of whom have no known diabetes, this group of patients should at least be considered to be at as high a risk for CI-AKI as those with established diabetes.

\section{Methods:}

This prospective observational study was conducted in the National Institute of Cardiovascular Diseases (NICVD), Dhaka from Jan 2012 to June 2012. The main objective of the study was to determine the relationship between level of admission blood glucose and contrast induced nephropathy after percutaneous coronary intervention in ACS patients not known to be diabetic. 60 patients were non diabetic patients with ACS with normal blood glucose (d"7.8 mmol/l or d"140 mg/dl) undergoing percutaneous coronary intervention (Group I) and 60 patients were non diabetic patients with ACS with high blood glucose (>7.8 mmol/l or $>140 \mathrm{mg} /$ dl) undergoing percutaneous coronary intervention (Group II). Group I = Non diabetic patients with ACS with normal blood glucose $(\leq 7.8 \mathrm{mmol} / \mathrm{l})$ undergoing percutaneous coronary intervention. Group II = Non diabetic patients with ACS with high blood glucose $(>7.8 \mathrm{mmol} / \mathrm{l})$ undergoing percutaneous coronary intervention.

To determine the relationship between level of admission blood glucose and contrast induced nephropathy after percutaneous coronary intervention in ACS patients not known to be diabetic. Specific objective of the study were- i) To observe the prevalence of high blood glucose level on admission ( $\geq 7.8 \mathrm{mmol} / \mathrm{l}$ or $\geq 140 \mathrm{mg} / \mathrm{dl}$ ) in ACS patients not known to be diabetic undergoing PCI. ii) To find out the relationship, if any, between the admission hyperglycemia and CIN in ACS patients not known to be diabetic undergoing PCI. iii) To assess the graded relationship, if any, between the degree of admission hyperglycemia and the occurrence of CIN in these patients.

\section{Results:}

The main objective of the study was to determine the relationship between level of admission blood 
glucose and contrast induced nephropathy after percutaneous coronary intervention in ACS patients not known to be diabetic.

Majority of the study patients belonged to 51-60 years age in both groups. The mean age was found $53.6 \pm 10.4$ years in Group I and 53.7 \pm 11.3 years in Group II. The mean age difference was not significant between two groups. Mean body mass index of the group I was $24.6 \pm 3.4$ and that of group II was $24.8 \pm 3.1$.BMI demonstrates that $36 \%$ of patients in group I were overweight, $16 \%$ obese, $41 \%$ normal weight and $7 \%$ underweight. In group II, $37 \%$ of the patients were overweight, $13 \%$ obese and $50 \%$ normal weight. No significant difference was observed between the groups in terms of BMI.38 (64\%) patients in group I and $36(60 \%)$ patients in group II were smokers. In group I, 33 (55\%) patients were hypertensive and in group II,
37 (61\%) patients were hypertensive. Dyslipidemia was found in 19 (32\%) and 16(27\%) patients and family history of CAD was found 8 (13\%) and 11 (18\%) patients in group I and group II respectively. No significant difference was observed between the groups in terms of risk factors.

Observing the ACS types , $15 \%$ of patients in group I had UA, 25\% NSTEMI, and 60\% STEMI. In group II, $14 \%$ of the patients had UA, $22 \%$ NSTEMI and $65 \%$ STEMI. No significant difference was observed between the groups in terms of ACS types $(p>0.05)$ (Table-II).

In group I, $32 \%$ of patients received $\leq 150 \mathrm{ml}$ of contrast and $68 \%$ patients received $>150 \mathrm{ml}$ of contrast. But in group II, $37 \%$ of patients received $\leq 150 \mathrm{ml}$ of contrast volume and $63 \%$ patients received $>150 \mathrm{ml}$. The volume of contrast used had no significant difference between the groups (Table-III).

Table-I

Baseline characteristics of the study subjects $(n=120)$.

\begin{tabular}{lcccccc}
\hline Age in years & \multicolumn{2}{c}{ Group I $(\mathrm{n}=60)$} & & \multicolumn{2}{c}{ Group II $(\mathrm{n}=60)$} & $\mathrm{p}$ value \\
\cline { 2 - 3 } & Number & $\%$ & & Number & $\%$ & \\
\hline$\leq 40$ & 6 & 10.0 & & 10 & 16.7 & \\
$41-50$ & 14 & 23.4 & & 13 & 21.7 & \\
$51-60$ & 27 & 44.9 & & 20 & 33.3 & 0.95 \\
$61-70$ & 9 & 15.0 & & 11 & 18.3 & \\
$>70$ & 4 & 6.7 & & 6 & 10.0 & \\
Body mass index & & & & & \\
$<18.5$ (Underweight) & 4 & 7.0 & & 0 & 0.0 & \\
$25-29.9$ (Overweight) & 21 & 36.0 & & 22 & 37.0 & \\
$\geq 30$ (Obese) & 10 & 16.0 & & 8 & 13.0 & \\
Smoking & 38 & 64.0 & & 36 & 60.0 & $0.71^{\text {ns }}$ \\
Hypertension & 33 & 55.0 & & 37 & 61.0 & $0.46^{\text {ns }}$ \\
Dyslipidaemia & 19 & 32.0 & & 16 & 27.0 & $0.55^{\text {ns }}$ \\
Family history of CAD & 8 & 13.0 & 11 & 18.0 & $0.45^{\text {ns }}$ \\
\hline
\end{tabular}

$\mathrm{s}=$ Significant; $\mathrm{ns}=$ Not significant; $\mathrm{p}$ value reached from unpaired $\mathrm{t}$-test

Table-II

Distribution of clinical subsets of patients with ACS $(n=120)$.

\begin{tabular}{lcccccc}
\hline Types of ACS & \multicolumn{2}{c}{ Group I $(\mathrm{n}=60)$} & & \multicolumn{2}{c}{ Group II $(\mathrm{n}=60)$} & p value \\
\cline { 2 - 3 } & Number & $\%$ & & Number & $\%$ & \\
\hline UA & 9 & 15.0 & & 8 & 14.0 & $0.79^{\mathrm{ns}}$ \\
NSTEMI & 15 & 25.0 & & 13 & 22.0 & $0.66^{\mathrm{ns}}$ \\
STEMI & 36 & 60.0 & & 39 & 65.0 & $0.57^{\mathrm{ns}}$ \\
\hline
\end{tabular}

ns $=$ Not significant; Data were analyzed using Pearson Chi-Square $\left(\chi^{2}\right)$ test. 
Table-III

Comparison of volume of contrast agent used between two groups $(n=120)$.

\begin{tabular}{|c|c|c|c|c|c|}
\hline \multirow{2}{*}{$\begin{array}{l}\text { Volume of contrast } \\
\text { (ml) }\end{array}$} & \multicolumn{2}{|c|}{ Group I $(n=60)$} & \multicolumn{2}{|c|}{ Group II (n =60) } & \multirow[t]{2}{*}{ p value } \\
\hline & Number & $\%$ & Number & $\%$ & \\
\hline$\leq 150$ & 19 & 32.0 & 22 & 37.0 & $0.56^{\mathrm{ns}}$ \\
\hline$>150$ & 41 & 68.0 & 38 & 63.0 & \\
\hline
\end{tabular}

$\mathrm{s}=$ Significant; Data were analyzed using Pearson Chi-Square $\left(\chi^{2}\right)$ test.

During procedure hypotension was higher in the group I (16\%) than that in the group II (9\%) but not statistically significant. Anorexia/vomiting was considerably higher in group II (17\%) than that in the group I (8\%) with no statistical significant difference. Other complications like arrhythmia ( $6 \%$ vs. $4 \%$ ), itching ( $6 \%$ vs. $8 \%$ ) and bronchospasm (13\% vs. $9 \%)$ were almost identically distributed between groups.

Table $\mathrm{V}$ shows the changes in the serum creatinine between baseline and day 2 among patients of study groups. The mean serum creatinine of group I was $1.0 \mathrm{mg} / \mathrm{dl}$ and $1.1 \mathrm{mg} / \mathrm{dl}$ at baseline and day 2 respectively, which was not statistically significant $(p=0.18)$. But in group II the mean serum creatinine was $1.0 \mathrm{mg} / \mathrm{dl}$ and $1.3 \mathrm{mg} / \mathrm{dl}$ on baseline and day 2 respectively. This differences were statistically significant $(p=0.001)$.

The above table shows the changes in the creatinine clearance rate among patients of study groups at different time interval. The mean $\mathrm{CCr}$ of group I was $76.6 \mathrm{ml} / \mathrm{min}$ and $73.7 \mathrm{ml} / \mathrm{min}$ at baseline and day 2 respectively and the change was statistically insignificant. The mean $\mathrm{CCr}$ in group II was $80.1 \mathrm{ml} / \mathrm{min}$ and $66.3 \mathrm{ml} / \mathrm{min}$ at baseline and day 2 respectively and this difference was statistically significant $(\mathrm{p}=0.001)$.

The above table shows when the most common definition of contrast induce nephropathy (as an increase in serum creatinine concentration $\geq 0.5$ $\mathrm{mg} / \mathrm{dl}$ or $\geq 25 \%$ increase of serum creatinine from baseline within 48 hours after exposure to contrast media) was used and we observed that CIN was higher in group II (25\%) than that of group I (5\%) which was statistically significant $(\mathrm{p}=0.001)$.

The above table shows the time of peak increase in the serum creatinine concentration among patients of CIN within 2 days of contrast administration, which was $0.65 \mathrm{mg} / \mathrm{dl}$ in group I as compared with $0.94 \mathrm{mg} / \mathrm{dl}$ in group II respectively. A statistically highly significant change in serum creatinine was observed on day 2 from baseline both in normal and high blood glucose group following PCI $(\mathrm{p}<0.001)$.

Analysis of factors associated with contrast induced nephropathy showing that, among 120 patients only 12 patients were $>70$ years of age where 3 of them developed CIN, that is not significant $(p=0.30) .21$ patients were female in comparison to 99 male patients, of them 5 female and 13 male patients developed CIN, that is also not significant $(\mathrm{p}=0.21)$. Among 50 hyperglycemic patients $(>7.8$ $\mathrm{mmol} / \mathrm{l}) 14$ patients developed CIN, that is significant $(p=0.008)$. More than $150 \mathrm{ml}$ contrast used in 65 patients, 15 of them developed CIN, which is statistically significant $(\mathrm{p}=0.048)$. Out of 100 patients 46 patients had low $\mathrm{Hb}(<13 \mathrm{gm} / \mathrm{dl}$ in male and $<12 \mathrm{gm} / \mathrm{dl}$ in female) and 74 patients had normal level, among them 8 and 10 patients develop CIN respectively, that is not statistically significant $(\mathrm{p}=0.56)$.

\section{Binary Logistic regression analysis}

\section{Model Fit:}

The regression model which included 3 predictor variables (Table IX) was first subjected to modelfit test. Hosmer and Lemeshow goodness-of-fit test demonstrated that the model was a good fit model which could predict $80 \%$ of the contrast induced nephropathy correctly $(\mathrm{p}=0.512)$.

Table $\mathrm{X}$ demonstrates the binary logistic regression analysis of Odds Ratio for characteristics of the subjects likely to cause contrast induced nephropathy (CIN). The variables revealed to be significantly associated or nearly significantly associated with CIN by univariate analysis were all entered into the model directly. Of the 3 variables high blood glucose and contrast volume $>150 \mathrm{ml}$ were found to be the independent 
Table-IV

Distribution of patients by contrast induced per procedural complications $(n=120)$.

\begin{tabular}{|c|c|c|c|c|c|}
\hline \multirow[t]{2}{*}{$\overline{\text { Complications }}$} & \multicolumn{2}{|c|}{ Group I $(n=60)$} & \multicolumn{2}{|c|}{ Group II $(\mathrm{n}=60)$} & \multirow[t]{2}{*}{ p value } \\
\hline & Number & $\%$ & Number & $\%$ & \\
\hline Anorexia/Vomiting & 5 & 8.0 & 10 & 17.0 & $0.16^{\mathrm{ns}}$ \\
\hline Itching & 6 & 9.0 & 8 & 13.0 & $0.57^{\mathrm{ns}}$ \\
\hline Hypotension & 10 & 16.0 & 6 & 9.0 & $0.28^{\mathrm{ns}}$ \\
\hline Arrhythmia & 6 & 9.0 & 4 & 6.0 & $0.50^{\mathrm{ns}}$ \\
\hline Bronchospasm & 8 & 13.0 & 6 & 9.0 & $0.56^{\mathrm{ns}}$ \\
\hline
\end{tabular}

ns = Not significant; Data were analyzed using Pearson Chi-Square $(\div 2)$ test.

Table-V

Changes in serum creatinine between baseline and day 2 among patients of study group $(n=120)$.

\begin{tabular}{lccc}
\hline Group & \multicolumn{2}{c}{ Serum creatinine } & p value \\
\cline { 2 - 4 } & Baseline & Day 2 & \\
& Mean \pm SD & $1.1 \pm 0.1$ & $0.18^{\text {ns }}$ \\
Group I $(\mathrm{n}=60)$ & $1.0 \pm 0.1$ & $1.3 \pm 0.5$ & $0.001^{\mathrm{s}}$ \\
Group II $(\mathrm{n}=60)$ & $1.0 \pm 0.2$ & & \\
\hline
\end{tabular}

$\mathrm{s}=$ Significant; $\mathrm{ns}=$ Not significant; Data were analyzed using paired student $\mathrm{t}$ - test.

Table-VI

Changes in creatinine clearance rate $(\mathrm{CCr})$ between baseline and day 2 among patients of study group $(n=120)$.

\begin{tabular}{lccc}
\hline Group & \multicolumn{2}{c}{ CCr } & p value \\
\cline { 2 - 3 } & Baseline & Day 2 & \\
& Mean \pm SD & Mean \pm SD & \\
\hline Group I $(\mathrm{n}=60)$ & $76.6 \pm 16.4$ & $73.7 \pm 14.9$ & $0.14^{\mathrm{ns}}$ \\
Group II (n=60) & $80.1 \pm 19.7$ & $66.3 \pm 20.8$ & $0.001^{\mathrm{s}}$ \\
\hline
\end{tabular}

$\mathrm{s}=$ Significant; Data were analyzed using paired student $\mathrm{t}$ - test.

Table-VII

Incidence of contrast induced nephropathy among studied patients $(n=120)$.

\begin{tabular}{|c|c|c|c|c|c|}
\hline \multirow[t]{3}{*}{ Group } & \multicolumn{4}{|c|}{ CIN } & \multirow[t]{3}{*}{$\mathrm{p}$ value } \\
\hline & \multicolumn{2}{|c|}{ Developed } & \multicolumn{2}{|c|}{ Not developed } & \\
\hline & Number & $\%$ & Number & $\%$ & \\
\hline Group I $(n=60)$ & 3 & 5.0 & 57 & 95.0 & $0.001^{\mathrm{s}}$ \\
\hline Group II ( $\mathrm{n}=60)$ & 15 & 25.0 & 45 & 75.0 & \\
\hline
\end{tabular}

$\mathrm{s}=$ Not significant; Data were analyzed using Pearson Chi-Square $\left(\div^{2}\right)$ test. 


\section{Table-VIII}

Changes in serum creatinine between baseline and day 2 among patients of CIN $(n=18)$.

\begin{tabular}{lccc}
\hline Group & \multicolumn{2}{c}{ Serum creatinine } & p value \\
\cline { 2 - 3 } & Baseline & Day 2 & \\
\hline Group I $(\mathrm{n}=3)$ & $0.75 \pm 0.21$ & Mean $\pm \mathrm{SD}$ & $0.0001^{\mathrm{s}}$ \\
Group II $(\mathrm{n}=15)$ & $0.96 \pm 0.25$ & $1.4 \pm 0.01$ & $0.0001^{\mathrm{s}}$ \\
\hline
\end{tabular}

$\mathrm{s}=$ Significant; Data were analyzed using paired student $\mathrm{t}$ - test.

Table-IX

Factors associated with contrast induced nephropathy $(n=120)$.

\begin{tabular}{|c|c|c|c|c|c|}
\hline \multirow[t]{3}{*}{ Factors } & \multicolumn{4}{|c|}{ CIN } & \multirow[t]{3}{*}{$p$ value } \\
\hline & \multicolumn{2}{|c|}{ Developed $(n=18)$} & \multicolumn{2}{|c|}{ Not developed $(n=102)$} & \\
\hline & Number & $\%$ & Number & $\%$ & \\
\hline Age ( $\leq 70$ years $)$ & 15 & 83.3 & 93 & 91.2 & $0.30^{\mathrm{ns}}$ \\
\hline Sex (Male) & 13 & 72.2 & 86 & 84.3 & $0.21^{\mathrm{ns}}$ \\
\hline Blood Glucose (> 7.8mmol/l) & 14 & 77.8 & 45 & 44.1 & $0.008^{\mathrm{s}}$ \\
\hline d)Contrast volume exposure $(>150 \mathrm{ml})$ & 15 & 83.3 & 60 & 58.8 & $0.048^{\mathrm{s}}$ \\
\hline e)Hemoglobin (Low *) & 8 & 44.4 & 38 & 37.2 & $0.56^{\mathrm{ns}}$ \\
\hline
\end{tabular}

$\mathrm{s}=$ significant; $\mathrm{ns}=$ Not significant; Data were analyzed using Pearson Chi-Square test.

*low $\mathrm{Hb}=$ Male $<13 \mathrm{gm} / \mathrm{dl}$, female $<12 \mathrm{gm} / \mathrm{dl}$; **normal $\mathrm{Hb}=$ Male $\geq 13 \mathrm{gm} / \mathrm{dl}$, female $\geq 12 \mathrm{gm} / \mathrm{dl}^{23}$

Table-X

Independent predictors for contrast induced nephropathy.

\begin{tabular}{|c|c|c|c|c|}
\hline \multirow[t]{2}{*}{$\overline{\text { Variables of interest }}$} & \multirow{2}{*}{$\begin{array}{c}\text { Univariate analysis } \\
\text { ( } p \text { value) }\end{array}$} & \multicolumn{3}{|c|}{ Multivariate analysis } \\
\hline & & OR & $95 \% \mathrm{CI}$ of OR & $\mathrm{p}$ value \\
\hline Age $>70$ yrs & 3.81 & $0.413-12.764$ & $0.26^{\mathrm{ns}}$ & \\
\hline High Blood Glucose $(>7.8 \mathrm{mmol} / \mathrm{l})$ & 0.01 & 6.48 & $1.343-32.612$ & $0.02^{\mathrm{s}}$ \\
\hline Contrast volume $>150 \mathrm{ml}$ & 0.03 & 2.79 & $0.132-5.128$ & $0.03 \mathrm{~s}$ \\
\hline
\end{tabular}

$\mathrm{s}=$ Significant; ns= Not significant; Multivariate analysis:

predictors of CIN with ORs being 6.48 and 2.79 respectively. This means that the patients subjected to PCI having high blood glucose were at 6 times (95\% CI of OR=1.343-32.612) higher risk of developing CIN then normal blood glucose and more than 2 times $(95 \%$ CI of OR=0.132-5.128) higher risk of developing CIN when contrast volume $>150 \mathrm{ml}(\mathrm{p}=0.03)$.

\section{Discussion:}

Contrast induced acute kidney injury is a complication of coronary angiography that occurs commonly in the setting of acute myocardial infarction and is associated with severe adverse events, including permanent renal impairment, higher in hospital and long term mortality, recurrent ischemic events, increased length of hospital stay and higher costs. Proposed pathophysiologic mechanisms through which contrast administration may potentiate renal injury include oxidative stress, free radical damage, and endothelial dysfunction. All of these processes also are activated in the setting of hyperglycemia, which is common in patients with acute coronary syndrome and has adverse prognostic implications, particularly among those who do not have established diabetes. So, it is possible that a combination of pre-procedural hyperglycemia and contrast exposure during coronary angiography could significantly increase the risk of contrast induced acute kidney injury. ${ }^{13}$ 
The current study was intended to find whether there is any relationship between level of admission blood glucose and contrast induced nephropathy after PCI in ACS patients not known to be diabetic. The mean age of patients in groupI was $54.6 \pm 10.3$ years, and in group-II it was 53.5 \pm 11.5 years. Among all study patients, highest number of patients was in the age group 51-60. That is similar to studies conducted by other Bangladeshi authors. ${ }^{14-17}$ However Rudnick and Kini have observed higher mean age which may be due to increased life expectancy in western country. ${ }^{18,} 19$

The majority of patient was male $82 \%$ in group I and $88 \%$ in group II with a male to female ratio $5.66: 1$ in the whole study population. The number of female patients were less in almost all previous studies. $3,14,16,19$ The mean BMI of group-I was $25.5 \pm 3.6 \mathrm{~kg} / \mathrm{m}^{2}$ and group-II was $24.7 \pm 3.0 \mathrm{~kg} / \mathrm{m}^{2}$. $42 \%$ patients in group I and $52 \%$ patients in group II belongs to normal weight group, similar to Hossain. ${ }^{14}$ No statistically significant difference was found between two groups in terms of mean BMI $(\mathrm{P}>0.05)$. However Peter and Tepel found that majority of patients were overweight, may be due to high BMI in western people. ${ }^{1,20}$

Among the risk factors for ischemic heart disease smoking was the commonest, $70 \%$ in group I and $66 \%$ in group II. This was followed by Hypertension (60\% vs. $68 \%$ ), Dyslipidaemia (32\% vs. $26 \%$ ) and positive family history of coronary artery disease ( $14 \%$ vs. $20 \%$ ) in a decreasing order of frequency. However, there was no statistically significant difference of incidence of these risk factors between the two groups. The results were consistent with the studies conducted by others. ${ }^{16,17,20,22,23}$ These data were almost similar to other studies in Bangladesh. One study showed that smoking was the commonest $(62.16 \%)$ risk factor. ${ }^{24}$

Considering ACS patients, Unstable angina was $12 \%$, NSTEMI was $24 \%$ and STEMI was $64 \%$ in group I patients. Whereas in group II 10\% patients had unstable angina, 20\% had NSTEMI and 70\% patients had STEMI. No significant difference was observed regarding clinical diagnosis between the groups. Hossain also found less number of unstable angina patients than myocardial infarction in his study. ${ }^{14}$ But Nikolsky found about half of the patients had unstable angina. ${ }^{23}$
The volume of contrast administered (d"150ml), in normal blood glucose group was 30\% and high blood glucose group was $36 \%$ but $>150 \mathrm{ml}$ of contrast was administered $70 \%$ in normal blood glucose group and $64 \%$ in high blood glucose group. The difference in receiving contrast volume between two groups was not statistically significant.

About per-procedural complications related to contrast administration, hypotension was higher in group I than that in group II but not statistically significant. Anorexia/vomiting were considerably higher in the latter group than that in the former group. Other complications like arrhythmia (4\% vs. $2 \%$ ), itching ( $6 \%$ vs. $10 \%$ ) and bronchospasm ( $12 \%$ vs. $10 \%)$ were almost identical between two groups. Akteruzzaman and Stolker also reported slightly higher incidence of hypotension, other complications were negligible. ${ }^{11,13}$

The mean serum creatinine level of normal blood glucose group and high blood glucose group were $1.0 \mathrm{mg} / \mathrm{dl}$ and $1.0 \mathrm{mg} / \mathrm{dl}$ at baseline which experienced a rise on day 2 up to $1.1 \mathrm{mg} / \mathrm{dl}$ and 1.3 $\mathrm{mg} / \mathrm{dl}$ respectively. Changes in serum creatinine level in group I, between base line and day 2 was not significant. But in group II the peak increase in serum creatinine between baseline and day 2 was statistically significant. The result was consistent with Stolker, who also found more nephropathy among higher blood glucose groups. ${ }^{13}$

The mean creatinine clearance rates at baseline were $77.6 \mathrm{ml} / \mathrm{min}$ and $80.2 \mathrm{ml} / \mathrm{min}$ in group-I and group-II respectively which continued decreasing up to day 2 when it became $71.6 \mathrm{ml} / \mathrm{min}$ in normal blood glucose group and $67.3 \mathrm{ml} / \mathrm{min}$ in high blood glucose group. The decrease in creatinine clearance rate was not significant in group I, but it was statistically significant in group II. Stolker has shown less decrease in creatinine clearance rate in low blood glucose level in comparison to high blood glucose group. ${ }^{13}$

When the most common definition of contrast induced nephropathy (as an increase in the serum creatinine concentration $\geq 0.5 \mathrm{mg} / \mathrm{dl}$ or $\geq 25 \%$ from baseline value at 48 hours after exposure to contrast media) was used the incidence of CIN was $24 \%$ in high blood glucose group and $4 \%$ in the normal blood glucose group that includes 12 patients in high blood glucose group and 2 patients in normal blood glucose group. The result was 
statistically significant. Stolker ${ }^{13}$ also found development of CIN is more common among hyperglycemic non diabetic ACS patients in comparison to normoglycemic non diabetic ACS patients $(18,1 \%$ vs. $51.6 \%) .{ }^{13}$ Shaheen and Akteruzzaman also found increased incidence of CIN among patients with high blood glucose but they included both diabetic and non-diabetic patients in study population. ${ }^{11,17}$

When all study patients in both groups were considered, 14 patients developed CIN i.e. the overall incidence of CIN was found $14 \%$ in the present study. The finding of the present study was very close to those of other multiple studies on CIN. Marenzi found overall $14.5 \%$ patient developed contrast induced nephropathy, among them CIN occurred in $27 \%$ patients with acute hyperglycemia. ${ }^{22}$ Nikolsky found the incidence of CIN after percutaneous coronary intervention was $13.9 \% .{ }^{23}$ Shaheen found the incidence of CIN after coronary angiography and percutaneous coronary intervention was $10 \% .{ }^{17} \mathrm{McCullough}$ also stated that incidence of CIN can rise to $50 \%$ or more in patients with multiple risk markers. ${ }^{3}$

We found that, among patients with contrast induced nephropathy one patient had admission blood glucose $<6.1 \mathrm{mmol} / \mathrm{l}$, one patient had blood glucose within 6.1 to $7.8 \mathrm{mmol} / \mathrm{l}$, two patients were within range of 7.9 to $9.4 \mathrm{mmol} / \mathrm{l}, 4$ patients had blood glucose within 9.5 to $11.1 \mathrm{mmol} / \mathrm{l}$ and highest number of patients that is 4 patients had blood glucose above $11.1 \mathrm{mmol} / 1$. So, it was observed that gradual incremental increase in risk of CIN associated with higher admission blood glucose levels.

In the study by Stolker, reported that there was a strong association between level of blood glucose and incremental increase in contrast induced acute kidney injury risk in patients without diabetes (contrast induced acute kidney injury rates across their 5 glucose groups from lowest to highest were $8.2 \%, 9.9 \%, 12.4 \%, 14.9 \%, 24.3 \% ; \mathrm{p}<0.001$ ) which are compatible with the present study. ${ }^{13}$

Analysis of factors associated with contrast induced nephropathy showed that out of 14 patients who has developed CIN, 2 patients were $>70$ years old. Only 6 patients in our study population had more than 70 years of age, so age could not influence the overall incidence of CIN. The elderly are at increased risk of CIN with reported incidence of $11 \%$ in patients older than 70 years. ${ }^{4}$ Patients having high blood glucose $(>7.8 \mathrm{mmol} / \mathrm{l})$ and contrast volume exposure $>150 \mathrm{ml}$ were more frequently associated with contrast induced nephropathy than patients with normal blood glucose (d" $7.8 \mathrm{mmol} / \mathrm{l})$ and contrast volume exposure d" $150 \mathrm{ml}$. Among 50 patients having high blood glucose 12 patients developed CIN, whereas only 2 patients having normal blood glucose had developed CIN, which is significant. Total 33 patients received ? $150 \mathrm{ml}$ of contrast and only 2 patients developed CIN. But 67 patients received $>150 \mathrm{ml}$ of contrast and 12 patients developed CIN. The difference was statistically significant. The risk of CIN is minimal in patients receiving $<100 \mathrm{~mL}$ of contrast media. ${ }^{4}$ Each $100 \mathrm{ml}$ of contrast medium administered was associated with a significant increase of $12 \%$ in the risk of nephropathy. ${ }^{25}$

A total of 3 variables revealed to be significantly associated or near significantly associated with the development of CIN in univariate analyses i.e. age $>70$ years, high blood glucose $(>7.8 \mathrm{mmol} / \mathrm{l})$ and contrast volume $>150 \mathrm{ml}$. All of these variables are considered as recognized risk factors on the basis of a number of international studies. ${ }^{4}$

But in multivariate logistic regression analyses of the 3 variables, high blood glucose and contrast volume $>150 \mathrm{ml}$ were found to be the independent predictors of CIN with ORs being 6.46 and 2.78 respectively. This means that patients subjected to PCI having high blood glucose were at more than 6 times ( $95 \% \mathrm{CI}$ of OR $=1.321-32.606)$ higher risk of developing CIN than the patients having normal blood glucose $(p=0.02)$. Similarly patients having contrast volume $>150 \mathrm{ml}$ have 2 times (95\% $\mathrm{CI}$ of $\mathrm{OR}=0.12-5.125$ ) higher risk of developing CIN in high blood glucose group than the normal blood glucose group following PCI ( $p=0.04)$.

Regarding outcome of the study patients, no patient died in the present study and no patient developed acute renal failure requiring dialysis. In a study, it has been found the occurrence of acute renal failure requiring dialysis after coronary intervention is rare $(<1 \%){ }^{1}$

The serum creatinine of $100 \%$ patients in both groups returned to base line within two weeks. In 
group-II 98\% returned to base line within first week and $2 \%$ returned to base line on second week. But $100 \%$ patients of group-I serum creatinine returned to baseline within first week. The outcomes are consistent with most ofthe studies on CIN when it was reported that CIN usually recovered within two weeks. ${ }^{26}$

\section{Conclusion:}

This study reveals that patients admitted with acute coronary syndrome with high blood glucose not known to be diabetic are associated with increased incidence of contrast induced nephropathy after percutaneous coronary intervention. So, more attention should be paid to the blood glucose level of the patient before doing any coronary intervention, as contrast induced nephropathy is a common and important cause of iatrogenic acute renal dysfunction and carries significant risk of cardiac and non cardiac morbidity and mortality.

\section{Conflict of Interest - None.}

\section{References}

1. Tepel M, Aspelin P and Lameire N. Contrast-induced nephropathy : A clinical and evidence-based approach. Circulation 2006; 113: 1799-1806.

2. Alpert MA and Carlino C. Pre-procedural blood glucose levels: A new risk marker for contrast-induced acute kidney injury in patients without diabetes with acute myocardial infarction. J Am Coll Cardiol 2010; 55: 1441-1443.

3. McCullough PA, Adam A, Becker CR, Davidson C, Lameire N, Stacul F, et al. Epidemiology and prognostic implications of contrast induced nephropathy. Am J Cardiology 2006; 98: 5k-13k.

4. Pucelikova T, Dangas G \& Mehran R. Contrast induced nephropathy. Catheter Cardiovasc Interv 2008; 71: 62-72.

5. Capes SE, Hunt D, Malmberg K, Gerstein HC. Stress hyperglycemia and increased risk of death after myocardial infarction in patients with and without diabetes: a systemic overview. Lancet 2000; 355: 773778.

6. Petursson P, Herlitz J, Karisson T, Perers E, Hartfold M. Admission glycaemia and outcome after acute coronary syndrome. Int J Cardiol 2007; 116(3): 315-320.

7. Norhammer A, Tenerz A, Nilsson G, Hamsten A, Ryden L, Malmberg K. Glucose metabolism in patients with acute myocardial infarction and no previous diagnosis of diabetes mellitus: a prospective study. Lancet 2002; 359: $2140-2144$
8. Deedwania P, Kosoborod M, Barrett E, Ceriello A, Isley W, Mazzone T, et al. Hyperglycemia and Acute Coronary Syndrome: A Scientific Statement from the American Heart Association Diabetes Committee of the Council on Nutrition, Physical Activity, and Metabolism. Circulation 2008; 117: 1610-16119.

9. Mehran $R$ and Nikolsky. Contrast-induced nephropathy: Definition, epidemiology, and patients at risk. Kidney International 2006; 69: 511-515.

10. Owen RJ, Hiremath S, Myers A, Fraser-Hill M and Barrett B. Consensus guidelines for the prevention of contrast induced nephropathy. Can Amoc Radiol J 2014;65(2):46-105.

11. Akhtaruzzaman M. Impact of low hemoglobin on contrast-induced nephropathy after percutaneous coronary intervention.Thesis (MD Cardiology). Dhaka, Bangladesh: University of Dhaka. 2010.

12. Gleeson TG \& Bulugahapitiya S. Contrast-Induced nephropathy. AJR 2004; 183: 1673-1689.

13. Stolker JM, McCullough PA, Rao S, Inzucchi SE, Spertus JA, Maddox TM, et al. Pre-procedural glucose levels and the risk for contrast-induced acute kidney injury in patients undergoing coronary angiography. $J \mathrm{Am}$ Coll Cardiol 2010; 55(14): 1433-1440.

14. Hossain S. Comparison of nephrotoxic effect of isoosmolar and low-osmolar non-ionic contrast media in patient with chronic kidney disease undergoing coronary angiography.Thesis (MD Cardiology). Dhaka, Bangladesh: University of Dhaka. 2010.

15. Ali M, Reza SA, Uddin MJ, Rahman S, Rahman A, Momenuzzaman NAM, et al. In-hospital outcome of 500 cases of Percutaneous Coronary Intervention. Bangladesh Heart Journal 2006; 21(1): 29-34.

16. Hayder S. Comparison of ionic and nonionic contrast media in cardiac angiography; clinical, electrocardiographic and haemodynamicchanges. Thesis (MD Cardiology). Dhaka, Bangladesh: University of Dhaka. 1999.

17. Shaheen Md. Nephrotoxic effects of contrast medium in patients undergoing coronary angiography and percutaneous coronary intervention. MD thesis. Dhaka, Bangladesh: University of Dhaka. 2008.

18. Rudnick MR, Goldfarb S, Wexler L, Ludbrook PA, Murphy PJ, Halpern EF, et al. Nephrotoxicity of ionic and nonionic contrast media in 1196 patients: a randomized trial. The iohexol cooperative study. Kidney International 1995; 47: 254-261.

19. Solomon R. The role of osmolality in the incidence of contrast-induced nephropathy: A systemic review of angiographic contrast media in high risk patients. Kidney International 2005; 68: 2256-2263.

20. Peter A, Aubry P, Fransson SG, Strasser R, Willenbrock R \& Berg KJ. Nephrotoxic effects in high-risk patients undergoing angiography. N Engl J Med 2003; 348(6): 491-499. 
21. Tepel M, Giet MVD, Schwarzfeld C, Laufer U \& Zidek W. Prevention of radioghraphic contrast agent-induced reduction in renal function by acetylcsystine. $N$ Engl $J$ Med 2000; 343: 180-184.

22. Marenzi G, Assanelli E, Marana I, Lauri G, Campodonico J, Grazi M, et al. N-acetylcystine and contrast-induced nephropathy in primary angioplasty. $N$ Engl J Med 2006; 354: 2773-2782.

23. Nikolsky E, Mehran R, Lasic Z, Mintz GZ, Lansky AJ \& Dangas G. Low-haematocrit predicts contrast-induced nephropathy after percutaneous coronary intervention. Kidney International 2005; 67: 706-713.
24. Majumder AAA, Ali M, Rahman A, Hoque SA, Khan A and Ahmed M. Relationship between baseline Creactive protein and angiographic severity of coronary artery disease in patients with acute coronary syndrome. Bangladesh Heart Journal 2006; 21(1): 11-16.

25. Waybill MM \& Waybill PN. Contrast media-induced nephrotoxicity: Identification of patients at risk and algorithms for prevention. J Vasc Interv Radiol 2001; 12: 3-9.

26. Goldenberg I \& Matetzky S. Nephropathy induced by contrast media: Pathogensis, risk factors and preventive strategies. CMAJ 2005; 172(11): 1461-1471. 